\title{
Chronic Obstructive Pulmonary Disease in Never-Smoking Dairy Farmers
}

\author{
Saso Stoleski ${ }^{*}$ Jordan Minov, Jovanka Karadzinska-Bislimovska and \\ Dragan Mijakoski
}

Institute for Occupational Health of R. Macedonia - Skopje, WHO Collaborating Center, GA2LEN Collaborating Center, R. Macedonia

\begin{abstract}
Introduction: Work-related chronic obstructive pulmonary disease (COPD) represents a considerable part of the disease burden globally.

Objective: To assess the COPD prevalence and characteristics in never-smoking dairy farmers.

Materials and Methodology: We have conducted a cross-sectional study with 75 male dairy farmers aged 26 to 59 years, and compared them with equivalent number of male office workers similar by age, and duration of employment. Data on chronic respiratory symptoms, job history and daily activities were obtained by questionnaire. Lung functional testing of the examined subjects included baseline spirometry, and bronchodilator reversibility measurement.
\end{abstract}

Results: Dairy farmers showed higher prevalence of overall respiratory symptoms, but significant difference was noticed for cough, phlegm, and dyspnea. Dairy farmers had more prevalent work-related respiratory symptoms, being significant for overall symptoms, cough, and phlegm. The mean baseline values of spirometric parameters were lower in dairy farmers, but significance was reported for $\mathrm{FEV}_{1} / \mathrm{FVC}, \mathrm{MEF}_{50}, \mathrm{MEF}_{75}$, and $\mathrm{MEF}_{25-75}$. Dairy farmers had significantly higher COPD prevalence than office controls $(10.7 \%$ vs $2.7 \%, P=0,049)$. Dairy farmers and office controls showed significant association between COPD and age over 45 years. Dairy farmers had a significant association between COPD and employment duration of over 20 years $(P=0.023)$, but also between COPD and work-related chronic respiratory symptoms $(P=0.041)$.

Conclusion: The study findings favor the cause-effect association between job exposure to respiratory hazards, and development of persistent airway obstruction among dairy farmers.

Keywords: Airflow limitation, bronchodilator testing, farming, job exposure, questionnaire, spirometry.

\section{INTRODUCTION}

Farm work is already well familiar occupational hazard for the development of chronic respiratory symptoms and respiratory disorders. The most significant deal of dust, vapors, and gases exposure in farming occurs mainly in barns and animal confinement buildings [1]. Predominant part of this daily exposure is composed by dusts, bacteria, and moulds, but also by endotoxin and ammonia as substances that are often been measured and closely related to respiratory health $[2,3]$. Apart of these components, animal derived material, with special emphasizes to dander, hair and skin can be also associated with an increased risk of respiratory diseases [4].

Respiratory disorders in dairy farmers are properly documented for the last few decades. Many studies performed so far in dairy farmers across Europe, but also in the United States have shown increased rates of chronic

*Address correspondence to this author at the Center for Respiratory Functional Diagnostics, Institute for Occupational Health, WHO Collaborating Center and $\mathrm{GA}^{2} \mathrm{LEN}$ Collaborating Center, II Makedonska Brigada 43, 1000 Skopje, R. Macedonia; Tel: +389 71314 435;

Fax: +389 22621 428; E-mail: sstoleski@yahoo.com bronchitis (CB), hypersensitivity, occupational and workrelated asthma, and organic dust toxic syndrome $[5,6]$. Typical findings of chronic obstructive respiratory diseases have been reported by researchers, meaning presence of decreased flow rates, bronchial hyperresponsiveness (BHR), and increased wheezing, cough, and production of phlegm [7-10].

In their everyday work, farmers are exposed to a wide range of vapors, organic and inorganic dusts, fumes, and other chemical agents $[11,12]$. Some of the recent studies [13-15] have associated these known hazardous exposures with the presence of respiratory symptoms in farmers, but however, most of them succeeded in detection and measurement of only a few agents.

The existing literature review in this domain confirms the present evidence that chronic obstructive pulmonary disease (COPD) due to occupational exposures has significantly increased during the last few decades, and became a major source of morbidity in lots of occupations, and conclusively a relevant public health problem [16-18].

A vast number of epidemiological studies performed so far demonstrated that tobacco smoke is undoubtedly the main cause of COPD, nevertheless results from certain 
studies point out that population attributable fraction for COPD related to workplace exposures to dusts, gases, vapors, and fumes may be $15-20 \%$ in overall population and can reach up to $30 \%$ in never smokers $[19,20]$.

Having this in mind, and despite the well known fact that cigarette smoking is the best studied COPD risk factor, recent research in the field indicates that it is not the only one, showing a consistent evidence from epidemiological studies that chronic airflow limitation may be also developed among non-smokers occupationally exposed to dusts, gases, vapors, and fumes [21, 22].

Some earlier study findings showed that workplace exposure to toxic gases, grain dust in farms, as well as dust and fumes in factories [23] was strongly associated with COPD. American Thoracic Society (ATS) in 2003 conducted a large epidemiological survey focused on workplace derived factors connected to COPD. The survey detected that $15 \%$ of COPD cases were related to occupational exposure [24], while a subsequent follow-up performed afterwards has proven similar estimates [25].

There is a large amount of data, showing that job exposures in farming might be related with the chronic airway disorders, being different from known bronchial changes in asthma.

Scientific research also made difference between development of respiratory symptoms and existence of chronic airways obstruction determined by spirometry measurement. In most cases, this chronic airflow limitation is due to bronchial obstruction and damage in the parenchyma fibers [26], and leads to chronic peripheral lung inflammation [27].

Dust from cereal grains and feed for animals, manure gases, vapors derived from disinfectants, and components of micro-organisms, such as endotoxins and fungi are the key agricultural exposures mentioned as probable promoters of the airway inflammation. This process further leads to chronic airway lung disorder, fibrosis and wall thickening, and finally to emphysema [28]

In this current research our objective was to explore the prevalence and characteristics of COPD in never-smoking dairy farmers.

\section{MATERIALS AND METHODOLOGY}

\section{Design of the Study}

Our team at the Institute for Occupational Health of R. Macedonia, Skopje - WHO Collaborating Center for Occupational Health and GA2LEN Collaborating Center conducted a cross-sectional survey within the Center for Respiratory Functional Diagnostics in the period October 2013 - June 2014. The main objective was to explore the frequency of chronic respiratory symptoms, mean values of measured spirometric parameters, and COPD prevalence among never-smoking male dairy farmers, and compare them with the appropriate variables in a group of neversmoking male office workers. The Institute's ethics committee has approved the content of our study protocol, whereas each examined subject was informed and gave written consent before any involvement in the study.

\section{Subjects}

We have examined 52 male subjects, with age range 26 to 59 years involved as dairy farmers with employment duration of 5 to 40 years (mean duration 21.6 \pm 5.3 ).

The examined subjects were employed as dairy farmers, working inside confinement buildings, and exposed to: dust, inappropriate microclimate conditions, chemical hazards, vapors, gases, heavy manual work, animal contact, unfavorable body positions, and repetitive hand movements. Their main occupational activities were: preparation of fodder feeding and animal meals, milking, staying in the barn, preparation of straw, and hay making, cattle rising, as well as taking care about milk hygiene and health of the animals.

Depending on the exposure duration, the study subjects were divided in two subgroups: exposed less or more than 20 years.

In terms of the study title, all examined dairy farmers were never smokers, either non-smokers, never smoked at all, or they were daily smokers before with less than 100 cigarettes smoked in their total lifetime [29].

In order to compare the obtained results, we have examined a similar group of 52 male office workers matched to dairy farmers by age and duration of employment as controls.

The subjects who were diagnosed by physician to have some chronic respiratory disorder (asthma, COPD, bronchiectasis, etc.), or treated with bronchodilators and/or corticosteroids were not included in the study. Both groups did not comprise any subjects in whom either spirometry or bronchodilator reversibility testing was contraindicated [30].

\section{Questionnaire}

The study subjects were interviewed by a physician, also responsible for completion of the study questionnaire. It comprised data about job history, chronic respiratory symptoms within the previous 12 months, and their workrelatedness.

The work history was assessed by data concerning the previous and current job engagement, working hours, daily activities, working conditions, and use of protective equipment.

The European Community for Coal and Steel questionnaire, and the European Community Respiratory Health Survey questionnaire [31, 32] were used to collect data about the chronic respiratory symptoms in the previous 12 months (cough, phlegm, dyspnea, wheezing, and chest tightness).

We have also evaluated data about chronic respiratory diseases diagnosed by physician, environmental exposure to tobacco smoke (ETS), family history of COPD and chronic bronchitis, medication use, and other accompanying diseases in the study subjects.

Chronic respiratory symptoms were defined as workrelated if more than usual cough, phlegm, dyspnea, wheezing, and chest tightness were present during the daily work [33]. 
Exposure to tobacco combustion products caused by other people smoking (at home, workplace), i.e. as a presence of at least one smoker in the household and/or in the workplace [34, 35], was defined as ETS, also known as passive smoking. Furthermore, in order to fulfill some special study requirements, passive smokers were separated within two groups regarding the number of their daily hours of ETS exposure (less or more than four hours per day).

\section{Baseline Spirometry}

Measurements of forced vital capacity (FVC), forced expiratory volume in one second $\left(\mathrm{FEV}_{1}\right), \mathrm{FEV}_{1} / \mathrm{FVC}$ ratio, and maximal expiratory flow at $50 \%, 25 \%$, and $25-75 \%$ of $\mathrm{FVC}$ $\left(\mathrm{MEF}_{50}, \mathrm{MEF}_{25}\right.$, and $\mathrm{MEF}_{25-75}$, respectively), also known as the baseline spirometry, was recorded by the Ganshorn SanoScope LF8 (Ganshorn Medizin Electronic GmbH, Germany) spirometer. The best result out of three measurements the $\mathrm{FEV}_{1}$ values was recorded, being in the $5 \%$ range value. The spirometry results were given as percents of their predicted values due to the current European Respiratory Society (ERS) and ATS recommendations [30]. In order to derive the predicted values of spirometric parameters, we have used the combined reference equations for males aged 18 to 70 years, with a height range of 155-190 cm, given in the ERS statement [36].

\section{Bronchodilator Reversibility Testing}

Our team performed the bronchial reversibility testing following the actual GOLD spirometry guide [37]. According to this guide, spirometric measurements were performed before and 20 minutes after administration of 400 $\mu \mathrm{g}$ salbutamol by metered dose inhaler. COPD, characterized by a fixed airflow narrowing was defined if postbronchodilator $\mathrm{FEV}_{1} / \mathrm{FVC}$ remained less than 0.70 . The $\% \mathrm{FEV}_{1}$ reversibility ([post-bronchodilator $\mathrm{FEV}_{1}$ - prebronchodilator $\mathrm{FEV}_{1}$ ] / pre-bronchodilator $\mathrm{FEV}_{1} \mathrm{x}$ 100) determined the degree of $\mathrm{FEV}_{1}$ reversibility. In such cases, diagnosis of COPD was not negate if there was a significant $\mathrm{FEV}_{1}$ improvement (a change more than $12 \%$ and more than $200 \mathrm{~mL}$ compared to the baseline value) in the presence of fixed airflow limitation.

\section{Diagnosis of COPD}

The COPD diagnosis was established in accordance with the actual GOLD recommendations [38], i.e., COPD was determined by the presence of a post-bronchodilator $\mathrm{FEV}_{1} / \mathrm{FVC}$ less than 0.70 , showing persistent airflow limitation in those subjects who have reported dyspnea, chronic cough or phlegm, and/or a exposure history to the disease risk factors (tobacco smoke, gas cooking, heating fuels smoke, and/or workplace dusts and chemical hazards).

\section{Statistical Analysis}

Data description and analysis were conducted using Statistica for Windows version 7 and Epi info 6. Mean values with their standard deviation were used for expressing the continuous variables, while variables of category were presented as numbers and percents. We have used the chisquare test (or Fisher's exact test if recommended) in order to test differences in the frequency of chronic respiratory symptoms, whereas analysis and comparison of spirometric measurements in the study was done using independentsamples T-test. Statistically significant was reported a $P$ value of less than 0.05 . Regression analyses were performed

Table 1. Demographic characteristics of the study subjects.

\begin{tabular}{|c|c|c|}
\hline Variable & Dairy Farmers $(n=52)$ & Office Workers $(n=52)$ \\
\hline Mean age (years) & $49.4 \pm 5.1$ & $48.7 \pm 4.9$ \\
\hline Age range (years) & $26-59$ & $27-58$ \\
\hline Less than 45 years & $24(46.2 \%)$ & $27(51.9 \%)$ \\
\hline More than 45 years & $28(53.8 \%)$ & $25(48.1 \%)$ \\
\hline BMI $\left(\mathrm{kg} / \mathrm{m}^{2}\right)$ & $24.5 \pm 3.9$ & $25.1 \pm 3.7$ \\
\hline Mean duration of employment (years) & $21.6 \pm 5.3$ & $20.2 \pm 5.1$ \\
\hline Duration of employment less than 20 years & $25(48.1 \%)$ & $28(53.8 \%)$ \\
\hline Duration of employment more than 20 years & $27(51.9 \%)$ & $24(46.2 \%)$ \\
\hline Family history of COPD or CB & $6(11.5 \%)$ & $3(5.8 \%)$ \\
\hline Environmental ETS & $20(38.5 \%)$ & $18(34.6 \%)$ \\
\hline Exposed less than 4 hours & $13(25 \%)$ & $10(19.2 \%)$ \\
\hline Exposed more than 4 hours & $7(13.5 \%)$ & $8(15.4 \%)$ \\
\hline \multicolumn{3}{|l|}{ Accompanying diseases } \\
\hline Arterial hypertension & $8(15.4 \%)$ & $10(19.2 \%)$ \\
\hline Diabetes mellitus type 2 & $3(5.8 \%)$ & $4(7.7 \%)$ \\
\hline Peptic ulcer & $6(11.5 \%)$ & $5(9.6 \%)$ \\
\hline
\end{tabular}

Numerical data are expressed as mean value with standard deviation; frequencies as number and percentage of study subjects with certain variable.

BMI: body mass index; kg: kilogram; m: meter; COPD: chronic obstructive pulmonary disease; CB: chronic bronchitis; ETS: exposure to tobacco smoke. 
to explore the influence of age, body mass index (BMI), and ETS exposure on respiratory symptoms development.

\section{RESULTS}

Characteristics of the study subjects are presented in Table 1. They were alike in both groups (Table 1).

Dairy farmers showed a higher prevalence of overall respiratory symptoms in the last year compared to office controls. Significant difference was noticed for cough, phlegm, and dyspnea (Table 2).

Work-related respiratory symptoms in the last 12 months were more prevalent among dairy farmers in comparison with office workers. Significant difference was reached for overall work-related respiratory symptoms, cough, and phlegm (Table 3).

The mean baseline values of spirometric parameters were lower in dairy farmers. Significant difference was detected for $\mathrm{FEV}_{1} / \mathrm{FVC}_{0}, \mathrm{MEF}_{50}, \mathrm{MEF}_{75}$, and $\mathrm{MEF}_{25-75}$ (Table 4).

Dairy farmers had significantly lower mean postbronchodilator values of every spirometric parameter (Table 5). The mean $\mathrm{FEV}_{1}$ reversibility ( $\% \mathrm{FEV}_{1}$ reversibility) was significantly higher in dairy farmers $(11.1 \%$ vs $4.8 \%, \mathrm{P}=$ 0.019; Independent-samples T-test).

According to the obtained results in our study, criteria for diagnosis of COPD (post-bronchodilator $\mathrm{FEV}_{1} / \mathrm{FVC}$ less

Table 2. Prevalence of respiratory symptoms in the last 12 months in examined groups.

\begin{tabular}{|c|c|c|c|}
\hline Respiratory Symptoms in the Last 12 Months & Dairy Farmers $(\mathbf{n}=\mathbf{5 2})$ & Office Workers $(\mathbf{n}=\mathbf{5 2})$ & $\boldsymbol{P}$-Value* \\
\hline \hline Any respiratory symptom & $19(36.5 \%)$ & $8(15.4 \%)$ & 0.133 \\
\hline Cough & $17(32.7 \%)$ & $3(5.8 \%)$ & 0.038 \\
\hline Phlegm & $10(19.2 \%)$ & $2(3.8 \%)$ & 0.037 \\
\hline Dyspnea & $8(15.4 \%)$ & $4(7.7 \%)$ & 0.045 \\
\hline Wheezing & $6(11.6 \%)$ & $3(5.8 \%)$ & 0.505 \\
\hline Chest tightness & $5(9.6 \%)$ & 0.715 \\
\hline
\end{tabular}

Data are expressed as number and percentage of study subjects with certain variable.

*Tested by chi-square test or Fisher's exact test where appropriate.

Table 3. Prevalence of work-related respiratory symptoms among dairy farmers and office workers.

\begin{tabular}{|c|c|c|c|c|}
\hline Respiratory Symptoms in the Last 12 Months & Dairy Farmers $(n=52)$ & Office Workers $(n=52)$ & $P$-Value* & OR $(95 \%$ CI $)$ \\
\hline Any work-related respiratory symptoms & $16(30.8 \%)$ & $7(13.5 \%)$ & 0.034 & $2.86(0.97-8.68)$ \\
\hline Cough & $13(25 \%)$ & $5(9.6 \%)$ & 0.0381 & $3.13(0.93-11.15)$ \\
\hline Phlegm & $8(15.4 \%)$ & $2(3.8 \%)$ & 0.045 & $4.55(0.82-32.87)$ \\
\hline Dyspnea & $4(7.7 \%)$ & $1(1.9 \%)$ & 0.362 & $4.25(0.42-103.53)$ \\
\hline Wheezing & $3(5.8 \%)$ & $2(3.8 \%)$ & 0.646 & $1.53(0.20-13.79)$ \\
\hline Chest tightness & $3(5.8 \%)$ & $1(1.9 \%)$ & 0.617 & $3.12(0.27-80.71)$ \\
\hline
\end{tabular}

Data are expressed as number and percentage of study subjects with certain variable.

OR: odds ratio; CI: confidence interval.

*Tested using multivariate logistic regression adjusted for age, BMI and ETS exposure.

Table 4. Mean baseline values of spirometric parameters in the examined subjects.

\begin{tabular}{|c|c|c|c|}
\hline Spirometric Parameter & Dairy Farmers $(\mathbf{n}=\mathbf{5 2})$ & Office Workers $(\mathbf{n}=\mathbf{5 2})$ & $\boldsymbol{P}$-Value* \\
\hline \hline FVC (\% pred) & $85.3 \pm 9.4$ & $88.5 \pm 10.1$ & 0.0975 \\
\hline $\mathrm{FEV}_{1}$ (\% pred) & $81.4 \pm 8.7$ & $84.6 \pm 9.1$ & 0.0697 \\
$\mathrm{FEV}_{1} / \mathrm{FVC} \%$ & $72.8 \pm 4.3$ & $74.7 \pm 5.2$ & 0.0449 \\
$\mathrm{MEF}_{50}(\% \mathrm{pred})$ & $55.9 \pm 6.1$ & $60.5 \pm 5.9$ & 0.0002 \\
$\mathrm{MEF}_{75}(\% \mathrm{pred})$ & $53.7 \pm 5.7$ & $60.8 \pm 6.4$ & 0.0000 \\
\hline $\mathrm{MEF}_{25-75}(\% \mathrm{pred})$ & $61.8 \pm 6.3$ & $64.5 \pm 7.1$ & 0.0428 \\
\hline
\end{tabular}

Data are expressed as mean value with standard deviation.

FVC: forced vital capacity; $\mathrm{FEV}_{1}$ : forced expiratory volume in 1 second; $\mathrm{MEF}_{50}, \mathrm{MEF}_{75}, \mathrm{MEF}_{25-75}:$ maximal expiratory flow at $50 \%, 75 \%$, and $25-75 \%$ of $\mathrm{FVC}$, respectively; $\%$ pred: $\%$ of predicted value.

${ }^{*}$ Tested by independent-sample $T$-test. 
Table 5. Mean post-bronchodilator values of spirometric parameters in the examined subjects.

\begin{tabular}{|c|c|c|c|}
\hline Spirometric Parameter & Dairy Farmers (n= 52) & Office Workers (n= 52) & $\boldsymbol{P}_{\text {-Value* }}^{*}$ \\
\hline \hline FVC (\% pred) & $88.1 \pm 10.3$ & $92.3 \pm 10.1$ & 0.0382 \\
\hline $\mathrm{FEV}_{1}$ (\% pred) & $83.2 \pm 8.1$ & $87.6 \pm 7.9$ & 0.0060 \\
$\mathrm{FEV}_{1} / \mathrm{FVC} \%$ & $73.6 \pm 4.2$ & $75.8 \pm 4.5$ & 0.0114 \\
$\mathrm{MEF}_{50}$ (\% pred) & $57.6 \pm 6.5$ & $62.4 \pm 6.1$ & 0.0002 \\
$\mathrm{MEF}_{75}$ (\% pred) & $56.2 \pm 5.8$ & $61.9 \pm 5.4$ & 0.0000 \\
\hline $\mathrm{MEF}_{25-75}$ (\% pred) & $63.1 \pm 6.5$ & $65.9 \pm 7.8$ & 0.0494 \\
\hline
\end{tabular}

Data are expressed as mean value with standard deviation.

$\mathrm{FVC}$ : forced vital capacity; $\mathrm{FEV}_{1}$ : forced expiratory volume in 1 second; $\mathrm{MEF}_{50}, \mathrm{MEF}_{75}, \mathrm{MEF}_{25-75}$ : maximal expiratory flow at $50 \%, 75 \%$, and $25-75 \%$ of $\mathrm{FVC}$, respectively; $\%$ pred: $\%$ of predicted value.

${ }^{*}$ Tested by independent-sample $T$-test.

than 0.70$)$ were fulfilled by eight subjects (10.7\%) among dairy farmers, and two subjects $(2.7 \%)$ among office workers (10.7\% vs 2.7\%, $\mathrm{P}=0,049$; Chi-square test) (Fig. 1).

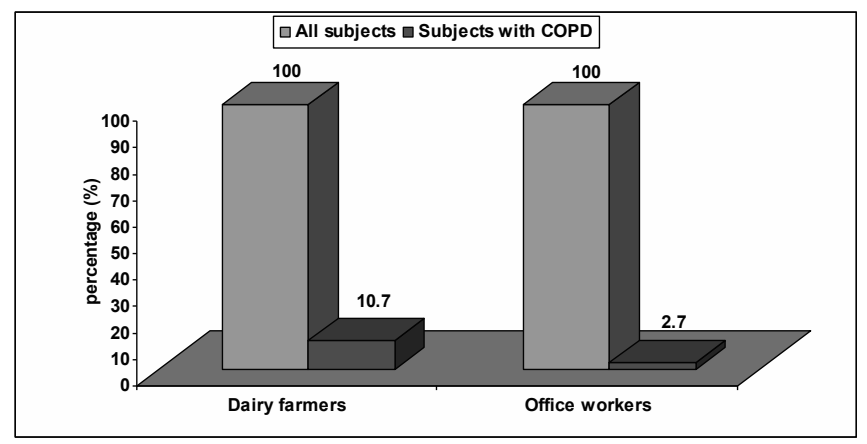

Fig. (1). Prevalence of COPD in the study subjects.

Mean $\mathrm{FVC}, \mathrm{FEV}_{1}$, and $\mathrm{MEF}_{25-75}$ values in dairy farmers with diagnosed COPD were 83.8 $\pm 4.9,81.2 \pm 5.3$, and $60.4 \pm 5.2$, while those in office workers with diagnosed COPD were $86 \pm 1.4,82.6 \pm 1.4$, and $63 \pm 1.4$ respectively.

Work-relatedness of the chronic respiratory symptoms was reported by every examined dairy farmer with diagnosed COPD, while COPD office controls did not report any workrelatedness to the symptoms. Concerning COPD severity classification due to GOLD 2010 [39], we have found six COPD cases in dairy farmers categorized as a mild COPD $\left(\mathrm{FEV}_{1} / \mathrm{FVC}<0.70 ; \mathrm{FEV} 1 \geq 80 \%\right.$ predicted $)$, and two cases with $\mathrm{COPD}$ among dairy farmers categorized as a moderate $\mathrm{COPD}\left(\mathrm{FEV}_{1} / \mathrm{FVC}<0.70 ; 50 \% \leq \mathrm{FEV}_{1}<80 \%\right.$ predicted $)$. The two confirmed COPD cases in office workers were categorized as a mild COPD.

Both dairy farmers and office controls had significant association between COPD and age over 45 years $(P=0.032$ vs $P=0.048$, respectively). Dairy farmers showed a significant association between COPD and employment duration of over 20 years $(P=0.023)$, as well as workrelated chronic respiratory symptoms $(P=0.041)$. There was no significant association between COPD and some other variables (BMI, family history of COPD or $\mathrm{CB}$, and environmental ETS), neither in dairy farmers, nor office workers.

\section{DISCUSSION}

Globally, COPD remains one of most important factors for both morbidity and mortality. The existing facts showed that smoking is the most important causative factor, but it is regularly accompanied by a vast number of occupational and environmental exposures. The current study explored the influence of specific workplace exposure among neversmoking dairy farmers on COPD developing and its characteristics. In both dairy farmers and controls, a relatively big number of passive smokers were noticed, being alike to its registered frequency in our country already documented in the previous studies [40]. This also indicates that so far there are still insufficient activities focused on smoking cessation nationwide.

The supreme interest in smoking, as a proven major risk factor for COPD development, has overshadowed the influence of non-smoking causes. However, Husman and colleagues [41] have put the occupation in relation with COPD in their longitudinal study among farmers and nonfarming workers in Finland, showing the presence of disease in $2.7 \%$ of farmers compared to $0.7 \%$ of non-farming workers. This way, they proved the adverse effect of occupational exposure in farming independent of smoking, indicating that $\mathrm{CB}$ is a work-related disease among farmers.

Dalphin et al. started the research into COPD in agricultural workers several decades ago, exploring the prevalence of $\mathrm{CB}$ and respiratory function in French dairy farmers. They gave the conclusion that dairy farmers were at risk for development of both $\mathrm{CB}$ and an airway obstruction [2]. Furthermore, Greskevitch et al. [42], were involved in a survey to study mortality and morbidity in agricultural workers linked to respiratory pathology. According to their results, crop farm workers and livestock farm workers showed significantly increased mortality related to respiratory conditions. Concerning the smoking habit in farmers, findings have shown that ex-smokers had higher prevalence of asthma, compared to non-smokers.

In our study, we have registered higher prevalence of overall chronic respiratory symptoms in the previous year in dairy farmers compared to office controls, being significantly frequent for cough, phlegm and dyspnea. 
Similar results about the prevalence of these symptoms in farmers were obtained by numerous studies. Radon et al., based on the results of the European Farmers' project showed a higher prevalence of chronic phlegm in animal farmers compared to the general population [43]. Heading in this direction, the research in Switzerland concluded that agricultural work was closely related to the CB risk and phlegm production in comparison with the general public [44]. Nevertheless, presence of chronic respiratory symptoms reporting did not always match the level of chronic airflow limitation determined by spirometry.

Dairy farmers and their respiratory health were in focus of numerous studies in France. According to Dalphin et al. [2], examined group of 250 dairy farmers had a significantly higher prevalence of $\mathrm{CB}(12 \%)$, compared to matched control subjects $(6 \%)$. These findings were most likely present in subjects aged 40 years or more, but also in nonsmokers. Another survey [7], have shown a $6.4 \%$ rate of CB among dairy farmers versus $0.7 \%$ in non-exposed controls, reporting an increase in the $\mathrm{CB}$ frequency among smokers, both exposed and controls, whereas the exposure effect was higher or equal to the effect of smoking on CB.

Our actual research confirmed that work-related respiratory symptoms in the previous year were more prevalent among dairy farmers compared to office controls reaching significance for overall work-related respiratory symptoms, cough, and phlegm, which is in accordance with some previous studies. The Croatian study was focused on the issue of $\mathrm{CB}$ in 236 livestock farm-workers, dealing with dairy cattle, and compared the results with 165 food packing workers [45]. The CB frequency was significantly higher among male farm-workers $(21.9 \%)$ compared with controls $(6.7 \%),(P<0.05)$. The frequency was higher among smokers $(27.6 \%)$ versus non-smokers $(6.5 \%),(P<0.05)$. Another study that was focused on the $\mathrm{CB}$ prevalence in farm workers with no breeding or managing livestock, was that of Kern et al. [46], showing significantly higher rate of $\mathrm{CB}$ in male farm workers $(20.9 \%)$, compared to controls $(7.4 \%),(P$ $<0.001)$. On the other hand, smokers had a higher $\mathrm{CB}$ prevalence $(30.2 \%)$ in comparison with non-smokers $(6.9 \%)$, $(P<0.001)$.

Recent Finnish study among a larger group of farmers [47] showed an association between CB, atopy, and smoking $(\mathrm{RR}=1.43$ and $\mathrm{RR}=2.43$ respectively), whereas a similar study in Norway [48] reported that the CB prevalence was highest among full-time farmers with livestock production (11.2\%), while CB frequency was lowest among part-time farmers without livestock production (4.4\%). A significant influence of smoking was described concerning the prevalence of CB (5.8\% in never smokers and $13.5 \%$ in ever smokers).

Concerning lung function testing, we have found that mean baseline spirometric values were lower in dairy farmers showing significance for $\mathrm{FEV}_{1} / \mathrm{FVC}^{\circ}, \mathrm{MEF}_{50}$, $\mathrm{MEF}_{75}$, and $\mathrm{MEF}_{25-75}$.

The CB prevalence and COPD development was studied by Eduard et al. and compared between crop and livestock farmers [10]. Based on this research they have concluded that livestock farmers suffered from both those conditions, having an odds ratio of 1.9 for $\mathrm{CB}$, and 1.4 for COPD. This study explored the lung function among examined farmers, as well as the effect of exposure to biological agents. FEV had a significant reduction, whereas FVC did not. Despite a significantly lower $\mathrm{FEV}_{1}$ in atopic farmers, there was no significant relationship between atopy, CB, COPD and FVC. Nevertheless, the exposure effects and their influence on COPD were significantly increased in atopic farmers.

In order to confirm the COPD diagnosis in our study subjects, defined as a post-bronchodilator $\mathrm{FEV}_{1} / \mathrm{FVC}$ less than 0.70 , a bronchodilator reversibility test was performed. This procedure was done due to actual GOLD recommendations, requiring the post-bronchodilator spirometry for both COPD diagnosis and severity assessment, having in mind that the degree of airflow limitation reversibility (measurements of $\mathrm{FEV}_{1}$ before and after bronchodilator administration) is no longer mandatory or recommended.

The prevalence of COPD in our study was significantly higher in dairy farmers $(10.7 \%)$ compared to office controls, confirming the increased risk for COPD development in farming occupations. Our results were similar to those the study performed by Miravitlles et al. [49] exploring the prevalence of COPD among Spanish population. They reported an overall COPD prevalence of $10.2 \%$ (95\% CI $9.2 \%$ to $11.1 \%$ ) out of 3802 participants with good-quality postbronchodilator spirometry, being higher in men $(15.1 \%)$ than in women $(5.6 \%)$.

Earlier study findings showed that ambient exposure to grain dust in farms [41] was related to COPD. In 2003, ATS conducted a large epidemiological survey focused on workplace factors related to COPD, and discovered that approximately $15 \%$ of COPD cases were related to occupational exposure [24], while a subsequent follow-up determined similar results [25].

COPD among non-smoking animal farmers working inside confined buildings was studied also by Monsó et al. [50]. COPD was found in 18 out of 105 examined farmers $(17.1 \%) .8$ cases $(7.6 \%)$ had a moderate diseases form, while 3 cases $(2.9 \%)$ had severe COPD. A dose-relationship between COPD, dust, and endotoxin exposure was also determined, and the highest COPD prevalence was reported in subjects exposed to both dust and endotoxin.

Having in mind the longitudinal study data, Hnizdo et al. [51] concerning the airway obstruction due to occupation, reported that among Mexican-Americans the largest percentage $(32.0 \%)$ of attributable fraction was connected to agriculture. Never smoking farmers compared to never smoking subjects from other occupations reported a 1.6-fold increased risk for non-reversible airways obstruction in farmers. Similar to these findings, the frequency of COPD GOLD I or higher was $24.5 \%$ among farmers who never smoked, versus $15.9 \%$ in other subjects who never smoked and had occupations different from farming $(P<0.017)$.

Concerning the subjects' age range in our study, among both groups, COPD was closely related to age over 45 years, as an explanation about the cumulative effect of different occupational and environmental exposures during the lifetime among the predisposed subjects. Also, we have detected a significant association between COPD and job exposure duration of over 20 years in dairy farmers. On the 
other hand, their COPD was associated with the work-related chronic respiratory symptoms.

Lamprecht et al., performing the survey of 1258 adults aged over 40 years [52] detected that $7.7 \%$ of the COPD risk was farming related, while mild COPD was present in about $30 \%$ of the subjects. Regarding the subjects' age groups, Iversen et al. [53] exploring $\mathrm{CB}$ in Danish farmers found a $23.6 \% \mathrm{CB}$ prevalence. $17.9 \%$ of this was found in farmers aged 31 to 50 years, and $33 \%$ in farmers aged 51 to 70 years. The rates were highest among pig farmers (32.0\%), but also in both dairy and pig farmers $(28.4 \%)$. The lowest ones were registered in only dairy farmers $(17.5 \%)$ and farmers with no animals kept $(18.6 \%)$. Analyzing $\mathrm{CB}$ in randomly selected Swiss farmers, Danuser et al. [44] detected $16 \%$ prevalence rate, and showed a significant increase with age. The main risk factors for $\mathrm{CB}$ development were crop farming, age over 60 years, former smoking, and more than 4 hours daily spent in confinement buildings. Non-smoking Swiss farmers had $12 \%$ CB prevalence, significantly higher compared to general Swiss population (6.8\%).

Finally, the current research has its own limitation factors. Certain influence on the obtained data and their analyze could have the considerably low number of study participants in both groups, absence of workplace monitoring to clearly understand the impact of exposure type and degree on COPD development, as well as lack of atopy evaluation among the examined subjects. Furthermore, alike every cross-sectional survey, the results could be jeopardized by the influence of healthy workers' effect.

Nevertheless, this study has also its strength, translated into the research on the workplace exposure and its respiratory effects among never-smoking dairy farmers engaged in one specific farming job.

\section{CONCLUSION}

The actual study findings are in line with the results from other similar studies about the cause-effect association between job exposure to respiratory hazards among dairy farmers and development of persistent airway obstruction. This should further help in detection of critical points for action, but also indicate the need of adverse occupational exposures reduction through adequate preventive measures, use of respiratory protective equipment, and implementation of engineering controls.

\section{CONFLICT OF INTEREST}

The authors confirm that this article content has no conflict of interest.

\section{ACKNOWLEDGEMENTS}

Declared none.

\section{REFERENCES}

[1] Omland O. Exposure and respiratory health in farming in temperate zones - a review of the literature. Ann Agric Environ Med 2002; 9: 119-36.

[2] Dalphin JC, Bildstein F, Pernet D, Dubiez A, Depierre A. Prevalence of chronic bronchitis and respiratory function in a group of dairy farmers in the French Doubs province. Chest 1989; 95: 1244-7.

[3] Dalphin JC, Debieuvre D, Pernet D, et al. Prevalence and risk factors for chronic bronchitis and farmer's lung in French dairy farmers. Br J Ind Med 1993; 50: 941-44.

[4] Amishima M, Munakata M, Ohtsuka Y, et al. Dairy farmers have increased methacholine bronchial responsiveness independent of sensitization to mold antigens. Am J Respir Crit Care Med 1995; 151: 1794-8.

[5] Dalphin JC, Pernet D, Dubiez A, Debieuvre D, Allemand H, Depierre A. Etiologic factors of chronic bronchitis in dairy farmers. Case control study in the Doubs region of France. Chest 1993; 103: 417-21.

[6] Malmberg P. Health effects of organic dust exposure in dairy farmers. Am J Ind Med 1990; 17: 7-15.

[7] Dalphin JC, Dubiez A, Monnet E, et al. Prevalence of asthma and respiratory symptoms in dairy farmers in the French province of the Doubs. Am J Respir Crit Care Med 1998; 158: 1493-8.

[8] Chaudemanche $\mathrm{H}$, Monnet E, Westeel V, et al. Respiratory status in dairy farmers in France; cross sectional and longitudinal analyses. Occup Environ Med 2003; 60: 858-63.

[9] Iversen M, Kirychuk SP, Drost H, Jacobson LD. Human health effects of dust exposure in animal confinement buildings. J Agric Saf Health 2000; 6: 275-82.

[10] Eduard W, Pearce N, Douwes J. Chronic bronchitis, COPD, and lung function in farmers: the role of biological agents. Chest 2009; 136: 716-25.

[11] Eduard W, Douwes J, Omenaas E, et al. Do farming exposures cause or prevent asthma? Results from a study of adult Norwegian farmers. Thorax 2004; 59: 381-6.

[12] Thelin A, Tegler O, Rylander R. Lung reactions during poultry handling related to dust and bacterial endotoxin levels. Eur J Respir Dis 1984; 65: 266-71.

[13] Donham KJ, Cumro D, Reynolds SJ, et al. Dose-response relationships between occupational aerosol exposures and crossshift declines of lung function in poultry workers: recommendations for exposure limits. J Occup Environ Med 2000; 42: 260-9.

[14] Kirychuk S, Dosman JA, Reynolds SJ, et al. Total dust and endotoxin in poultry operations: comparison between cage and floor housing and respiratory effects in workers. J Occup Environ Med 2006; 48: 741-8.

[15] Eduard W, Douwes J, Mehl R, et al. Short term exposure to airborne microbial agents during farm work: exposure-response relations with eye and respiratory symptoms. Occup Environ Med 2001; 58: 113-8.

[16] Beclacke M.R. Chronic airflow limitations: its relationship to work in dusty occupations. Chest 1985; 88: 608-17.

[17] Meredith SK, Taylor VM, Mc Donald JC. Occupational respiratory disease in the United Kingdom: a report to the British Thoracic Society and the Society of Occupational Medicine by the SWORD project group. Br Ind Med 1991; 48: 292-8.

[18] Blanc P.D. Occupation and COPD: a brief review. J Asthma 2012; 49 (1): $2-4$.

[19] Balmes J, Becklake M, Blanc P, et al. American Thoracic Society Statement: Occupational contribution to the burden of airway disease. Am J Respir Crit Care Med. 2003; 167: 787-97.

[20] Trupin L, Earnest G, San Pedro M, et al. The occupational burden of chronic obstructive pulmonary disease. Eur Respir J 2003; 22: 462-9.

[21] Lamprecht B, McBurnie MA, Vollmer WM, et al. COPD in never smokers: results from the population-based burden of obstructive lung disease study. Chest 2011; 139(4): 752-63.

[22] Celli BR, Halbert RJ, Nordyke RJ, Schau B. Airway obstruction in never smokers: results from the Third National Health and Nutrition Examination Survey. Am J Med 2005;118(12): 1364-72.

[23] Becklake MR. Occupational exposures: evidence for a causal association with chronic obstructive pulmonary disease. Am Rev Respir Dis 1989; 140(pt 2): S85-S91.

[24] Balmes J, Becklake M, Blanc P, et al. Environmental and Occupational Health Assembly, American Thoracic Society. American Thoracic Society statement: occupational contribution to the burden of airway disease. Am J Respir Crit Care Med 2003; 167: 787-7. 
[25] Blanc PD, Toren K. Occupation in chronic obstructive pulmonary disease and chronic bronchitis: an update. Int $\mathrm{J}$ Tuberc Lung Dis 2007; 11: 251-57.

[26] Hogg JC, Macklem PT, Thurlbeck WM. Site and nature of airway obstruction in chronic obstructive lung disease. $\mathrm{N}$ Engl J Med 1968; 278: 1355-60.

[27] Cosio M, Ghezzo $\mathrm{H}$, Hogg $\mathrm{JC}$, et al. The relations between structural changes in small airways and pulmonary function tests. $\mathrm{N}$ Engl J Med 1978; 298: 1277-81.

[28] Schenker MB, Christiani D, Cormier Y, et al. Respiratory health hazard in agriculture. Am J Respir Crit Care Med 1998; 158: 1-76.

[29] World Health Organization. Guidelines for controlling and monitoring the tobacco epidemic. Geneva: WHO 1998.

[30] Miller MR, Hankinson J, Brusasco V, et al. Standardisation of spirometry. Eur Respir J 2005; 26: 319-38.

[31] Minette A. Questionnaire of the European Community for Coal and Steel (ECSC) on respiratory symptoms. 1987 - updating of the 1962 and 1967 questionnaires for studying chronic bronchitis and emphysema. Eur Respir J 1989; 2: 165-77.

[32] European Community Respiratory Health Survey. Variations in the prevalence of respiratory symptoms, self-reported asthma attacks, and use of asthma medication in the European Respiratory Health Survey (ECRHS). Eur Respir J 1996; 9: 687-95.

[33] Meijer E, Grobbe DE, Heederik DJJ. Health surveillance for occupational chronic obstructive disease. J Occup Environ Med 2001; 43: 444-50

[34] U.S. Department of Health and Human Services. The health consequences of smoking: chronic obstructive pulmonary disease. A report of the Surgeon General. US Department of Health and Human Services, Public Health Service, Office of the Assistant for Health, Office of Smoking and Health. DHHS Publication No. 8450205,1984

[35] Janson C, Chinn S, Jarvis D, Zock JP, Toren K, Burney P, for the European Community Respiratory Health Survey. Effects of passive smoking on respiratory symptoms, bronchial responsiveness, lung function, and total serum $\mathrm{IgE}$ in the European Community Respiratory Health Survey: a cross-sectional study. Lancet 2001; 358: 2103-9.

[36] Quanjer PH, Tammeling GJ, Cotes JE, Pedersen OF, Peslin R, Yernault JC. Lung volumes and forced ventilatory flows. Report Working Party Standardization of Lung Function Tests, European Community for Steel and Coal. Official Statement of the European Respiratory Society. Eur Respir J 1993; 6(16): 5-40.

[37] Spirometry Guide: 2010 Update. Available from: http://www.goldcopd.org/uploads/users/files/GOLD Spirometry 2 010.pdf. Assessed on November 202014.

[38] Global Strategy for the Diagnosis, Management, and Prevention of Chronic Obstructive Pulmonary Disease: 2014 Update. Available from: http://www.goldcopd.com/uploads/users/files/GOLD_Repor t 2014 Oct30.pdf [Assessed on November 20 2014].

[39] Global Strategy for the Diagnosis, Management, and Prevention of Chronic Obstructive Pulmonary Disease: 2010 Update. Available from: http://www.goldcopd.org/Guidelines/guideline-2010-goldreport.html [Assessed on November 20 2014].

[40] Minov J, Karadzinska-Bislimovska J, Vasilevska K, et al. Smoking among Macedonian workers five years after the anti-smoking campaign. Arh Hig Rada Toksikol 2012; 63: 207-13.

[41] Husman K, Koskenvuo M, Kaprio J, Terho E.O, Vohlonen I. Role of environment in the development of chronic bronchitis. Eur J Respir Dis Suppl 1987; 152: 57-63.

[42] Greskevitch M, Kullman G, Bang KM, Mazurek JM. Respiratory disease in agricultural workers: mortality and morbidity statistics. J Agromed 2007; 12(3): 5-10.

[43] Radon K, Garz S, Riess A, et al. Respiratory diseases in European farmers. Part II: Results of the European farmers' project. Pneumologie 2003; 57: 510-17.

[44] Danuser B, Weber C, Kunzli N, Schindler C, Nowak D. Respiratory symptoms in Swiss farmers: An epidemiological study of risk factors. Am J Ind Med 2001; 39: 410-8.

[45] Mustajbegovic J, Zuskin E, Schachter EN, et al. Respiratory findings in livestock farm-workers. J Occup Environ Med 2001; 43: 576-84.

[46] Kern J, Mustajbegovic J, Schachter EN, et al. Respiratory findings in farm-workers. J Occup Environ Med 2001; 43: 905-13.

[47] Terho EO, Koskenvou M, Kapria J: Atopy: a predisposing factor for chronic bronchitis. J Epidemiol Community Health 1995; 4: 296-8.

[48] Melbostad E, Eduard W, Magnus P. Chronic bronchitis in farmers. Scand J Work Environ Health 1997; 23: 271-80.

[49] Miravitlles M, Soriano JB, García-Río F, et al. Prevalence of COPD in Spain: impact of undiagnosed COPD on quality of life and daily life activities. Thorax 2009; 64(10): 863-8.

[50] Monsó E, Riu E, Radon K, et al. Chronic obstructive pulmonary disease in never-smoking animal farmers working inside confi nement buildings. Am J Ind Med 2004; 46(4): 357-62.

[51] Hnizdo E, Sullivan PA, Bang KM, Wagner G. Airflow obstruction attributable to work in industry and occupation among US race/ethnic groups: A study of NHANES III data. Am J Ind Med 2004; 46: 126-35.

[52] Lamprecht B, Schirnhofer L, Kaiser B, Studnicka M, Buist AS. Farming and the prevalence of non-reversible airways obstruction: results from a population-based study. Am J Ind Med 2007; 50: 421-6.

[53] Iversen M, Dahl R, Korsgaard J, Hallas T, Jensen EJ. Respiratory symptoms in Danish farmers: an epidemiological study of risk factors. Thorax 1988; 43: 872-7. 